\title{
La postura camaleónica de la violencia: el Poeta de La ciudad y los perros (1963) de Mario Vargas Llosa
}

\author{
" The challeonic posture of violence: the Poet of The \\ Time of the Hero (7963) of Mario Vargas Llosa
}

\begin{tabular}{l} 
Jesús Miguel Delgado Del Águila \\
\hline Universidad Nacional Mayor de San Marcos, Perú \\
\hline
\end{tabular}

\section{Resumen}

La configuración del personaje Alberto Fernández (el Poeta) de La ciudad y los perros (1963) es camaleónica en función de la violencia, por el hecho de asumir que su comportamiento, en algunas ocasiones, era agresivo para adquirir un respeto determinado; por el contrario, el personaje tenderá a querer experimentar un poco más su agresividad al tratar de derrotar al Jaguar y al querer vengarse por la muerte de su compañero Ricardo Arana. Asimismo, su lado humano se destaca (con esa actitud, se contrarresta esa violencia, la cual controla mayormente): es pacífico, sabe convivir en aquel espacio violento, no busca pleitos y llega también a convertirse en cobarde y delator (en el momento que es chantajeado por las autoridades del Leoncio Prado al no mencionar nada sobre la muerte del Esclavo, ya que de hacerlo se le expulsará por ser el autor de novelitas pornográficas que ha difundido en toda su sección).

Palabras clave: adaptación social, violencia, personaje, protagonista, análisis literario.

\section{Abstract}

The configuration of the character Alberto Fernandez (the Poet) of The Time of the Hero (1963) is chameleonic in terms of violence, due to the fact that he assumed that his behavior was sometimes aggressive in order to acquire a certain respect; on the contrary, the character will tend to want to experience a little more aggressiveness in trying to defeat the Jaguar and to seek revenge for the death of his companion Ricardo Arana. Also, he is conceived of his human side (it is with this attitude that would counteract that violence, which seems to control in its majority): it is something peaceful, knows how to live in that violent space, does not seek mostly lawsuits and even reaches the extreme to be a coward and informer (at the moment he is blackmailed by the authorities of Leoncio Prado not to mention anything about the death of the Slave, since to do so he will be expelled for being the author of pornographic novels that he has spread throughout his section).

Keywords: social adaptation, violence, character, protagonist, literary analysis.

Cómo citar este articulo:

DelgadoDelÁguila,J.M.(2019).Laposturacamaleónicadelaviolencia:elPoetadeLaciudadylosperros(1963)deMarioVargasLlosa.RevistaAmauta 17(33), pp.23-36. http://dx.doi.org/10.15648/am.33.2019.3

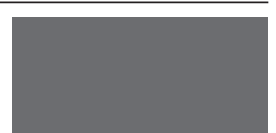

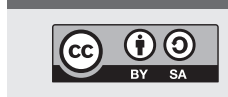

() 2019

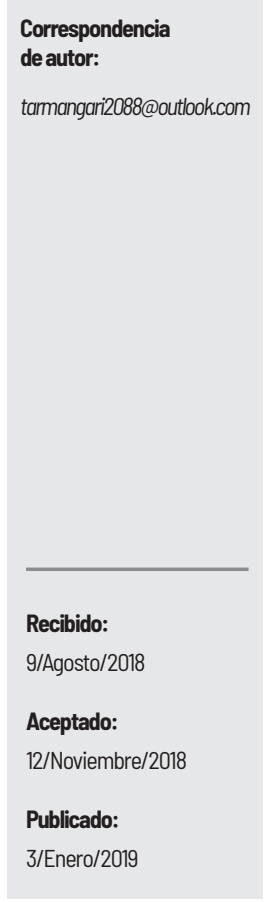




\section{Introducción}

Dos críticos literarios han abordado este tema de manera indirecta: Sara CastroKlarén (1992) y Sergio Vilela Galván (2003). El primer postulado alude a la configuración hecha en el personaje Alberto Fernández como un sujeto que razona con criterios coherentes para hallar al homicida del Esclavo; mientras que el segundo criterio aborda el fondo de este protagonista en función de la sociedad: el Poeta como representante del machismo y transgresor del autoritarismo de ese régimen militar, al ser escritor de novelitas porno, con la finalidad de generarse dinero y cigarrillos. Fuera de las impresiones que han tenido los críticos con respecto a este personaje, se hará un análisis en el que se aluda a la forma como organiza el Poeta sus mundos y de qué modo se introduce en ellos. La explicación a lo referido se ha segmentado en diez breves tratados. El primer tópico esclarece la configuración protagónica de Alberto Fernández, la cual se deduce de la misma novela como construcción histórica de los propios personajes. El segundo tratado abarca el término desarrollado por Landowski al referirse al camaleón: un sujeto que condiciona su manera de interactuar con el mundo. El tercer tema se refiere a la programación, que es indispensable para el personaje que requiere organizar su forma de ser para lograr algún propósito. El cuarto, el ajuste como el modo de autorregularse a las situaciones que se presenten. El quinto, la eficacia y la capacidad de razonar por parte del Poeta, quien destaca en la novela por las inferencias que deconstruye de lo acaecido. El sexto, las acciones que marcan una identidad frente a los demás. El séptimo punto alude a la necesidad del Poeta de comportarse como el Jaguar: el modelo violento de respeto en su colegio. El octavo, el riesgo de no llevar bien a cabo la regulación de una identidad condicionada. El noveno tópico se encarga de articular esas limitaciones que impiden que el Poeta sea como el Jaguar. Finalmente, como último punto, se abordará una característica del Poeta que lo asocia con el Esclavo, porque se trata de una acción de cobardía, el silencio condicionado. Estos diez modos de configurar al Poeta se incluirán, posteriormente, en triángulos jerárquicos, al igual que con lo elaborado sobre el Jaguar y el Esclavo; por lo tanto, se observarán sus construcciones y sus deconstrucciones, a partir de la necesidad que tienen ellos de manifestar su identidad. 


\section{El protagonista}

Alberto Fernández es importante para el desarrollo de la historia de La ciudad y los perros (1963), por lo tanto, se trata de otro protagonista más. El Poeta tiene el mismo problema del Jaguar: sus bases familiares están mal constituidas, aunque, a diferencia de él, goza de una comodidad económica. Este contratiempo no es un déficit del todo para el personaje cuando estudia en el Colegio Militar Leoncio Prado, debido a que sabe adaptarse a las circunstancias violentas que le exige esa pequeña sociedad: cuando tiene que pelearse, lo hará; de igual manera, si pretende quedarse callado. Esta postura camaleónica que adopta le permite marcar un límite en sus vivencias dentro y fuera de aquel colegio. En su sección, es conocido como el Poeta, puesto que vende a sus compañeros novelitas pornográficas y cartas de amor, con la finalidad de adquirir dinero y cigarrillos. Durante su vida militar, se hace amigo del Esclavo, quien resulta ser el personaje que le hace llegar hasta Teresa, chica de quien se enamora en un determinado período; pero Ricardo Arana también será un motivo por el que Alberto tome iniciativas para vengar su muerte (al realizar estas invectivas tendrá que ser un soplón): acusa al Jaguar como responsable del asesinato y delata los malos hábitos aprendidos y ejecutados por los chicos de su sección (el consumo de bebidas, los robos, el tirar contra y el maltrato). El Poeta tiene la oportunidad de enfrentarse con el Jaguar, no logra vencerlo, aunque pide que se haga justicia. Su reclamo no es atendido, porque denigra el Colegio Militar como institución; por ese motivo, se le chantajea con las novelitas pornográficas que escribió (razón que acredita su instantánea expulsión).

\section{El camaleón}

El Poeta cumple con las características que son propias del camaleón, término empleado por Eric Landowski (2007, pp.54-55), que lo define como a aquella persona que tiene la facilidad de distanciarse de un mundo para trasladarse a otro, de forma convencional y temporal; con ello, se logra que este se adapte como mejor le convenga. Añade que se trataba de un simple animal social (Landowski, 2007, p.60), que hace prevalecer lo natural, un querer ser definido exclusivamente por referencia a sí mismo como uno u otro -su meta es ser sí mismo, con perseverancia en su propio ser, por lo que se realiza su propio programa de vida-. El camaleón irá 
administrando hábilmente las apariencias, a fin de no dejar percibir en lo más mínimo su alteridad intrínseca en relación con el medio. Cualquier persona es miembro de muchos grupos diferentes a los que pertenece, sin necesidad de ser contradictorio; estos le proporcionan una identidad potencial, que es bastante importante según la situación -es un error pensar que la gente es la misma en todo el mundo, ya que uno se expone a la diferencia, de muchas maneras distintas, sin catalogarse en una única dimensión-. Mas, el advertir esta pluralidad de identidades en un solo sujeto aún resulta una idea complicada. Amartya Sen $(2007$, p.45) menciona que existe una clase de reduccionismo llamada filiación singular, concepto que se opone a la indiferencia hacia la identidad. Esta presupone que cualquier persona está sometida a incluirse únicamente a una sola colectividad: planteamiento erróneo, debido a que se sabe que cualquier ser humano real pertenece a muchos grupos diferentes, por medio del nacimiento, las asociaciones y las alianzas - con el Poeta es un caso excepcional, no solo es distinto para sus amigos que tiene en un determinado grupo social, como en el colegio o su entorno, sino que es diferente con cada persona que conoce: en el Leoncio Prado no se comportará de igual modo con el Esclavo que con el negro Vallano, el serrano Cava o el Jaguar. Este protagonista se ha adaptado a una forma conveniente para interrelacionarse eficazmente.

\section{La programación}

En el Poeta, es necesario observar cómo en él se ejerce la programación, la cual consiste, según Landowski (2009, p.30), en el permiso existente al sujeto en interactuar con tranquilidad, de una manera mecanicista y regular (continuidad); esta busca la transformación de los estados $(S \rightarrow 0)$, ya sea en un objeto 0 un sujeto tomado como objeto -Lacan (1997, p.94) sostiene que el hombre se convierte en signo, elemento y objeto del intercambio reglado-. Ahora, para que este objeto sea programable, por parte de un sujeto, es necesario que desempeñe su rol temático o esté programado. Inmediatamente, se cumple el "hacer ser" con respecto al individuo. En la novela de Mario Vargas Llosa, se observa cómo existe esta formalidad que permite visualizar el modo de llevar las relaciones con los objetos; en especial, con Alberto Fernández. La idea que tiene del bien está bien definida; sabe que esta le producirá un verdadero placer (el ayudar al Esclavo ante mucha violencia, el enamorarse de Teresa, el de proclamar la verdad al delatar las malas acciones de su sección 
o el luchar para hacer justicia por la muerte de su compañero). El Poeta cumple un doble rol en los procedimientos del lenguaje: primero, es un destinador por la razón de que asimila las concepciones del bien y el mal que se desarrollan en sus círculos sociales; $y$, segundo, es un destinatario porque manifiesta lo aprendido con mucho cuidado, puesto que él resulta ileso y sin secuelas que dañan su integridad. Cree sentirse capaz de organizar su vida, sin que las circunstancias alteren el rumbo de sus anhelos personales, tal como se aprecia en el diálogo establecido con el Esclavo.

-Es por eso que estás fregado - dice Alberto-. Todo el mundo sabe que tienes miedo. Hay que trompearse de vez en cuando para hacerse respetar. Si no, estarás reventado en la vida.

-Yo no voy a ser militar.

-Yo tampoco. Pero aquí eres militar aunque no quieras. Y lo que importa en el Ejército es ser bien macho, tener unos huevos de acero, ¿comprendes? 0 comes o te comen, no hay más remedio. A mí no me gusta que me coman.

-No me gusta pelear -dice el Esclavo-. Mejor dicho, no sé.

-Eso no se aprende - dice Alberto-. Es una cuestión de estómago. El teniente Gamboa dijo eso una vez.

-Es la pura verdad, ¿no? Yo no quiero ser militar pero aquí uno se hace más hombre. Aprende a defenderse y a conocer la vida.

-Pero tú no peleas mucho - dice el Esclavo-. Y sin embargo no te friegan.

-Yo me hago el loco, quiero decir, el pendejo. Eso también sirve, para que no te dominen. Si no te defiendes con uñas y dientes, ahí mismo se te montan encima.

-¿Tú vas a ser un poeta? -dice el Esclavo. 
- ¿Estás cojudo? Voy a ser ingeniero. Mi padre me mandará a estudiar a

Estados Unidos. Escribo cartas y novelitas para comprarme cigarrillos.

Pero eso no quiere decir nada. (Vargas Llosa, 2012, pp. 26-27)

La programación se trata de un hacer advenir (llegar) (Landowski, 2009, p. 81), que alcanzará resultados beneficiosos, como también desagradables. Si una programación presenta dificultades, puede frustrarse y conseguir lo insignificante o lo riesgoso. Aquello ocurre, siempre y cuando, existiera una falta de saber hacer que se presencia como una limitación en los comportamientos humanos, quienes tienden a depender de la motivación y el principio de intencionalidad. Eric Landowski (2009, p. 39) señala que hay dos formas de motivación: la strictu sensu, la cual motiva al "inventor de lo cotidiano" (el sujeto deseoso de cuestionar a cada instante) para redefinir el sentido que atribuye a las prácticas de los objetos - se fundamentan decisiones para abolir o instituir determinadas prácticas-: modo con el que construye diariamente su propio mundo, en cuanto se trata de un universo significante. El Poeta tiende muchas veces a esta manera de motivación: se autoprograma para que la relación con los sujetos esté restringida entre un término medio del uso del bien y el mal. En segundo lugar, encontramos una motivación que se limita a acompañar la realización de los programas de comportamiento socialmente regulados, en la que se explicita el valor simbólico que es posible asociarle. Se trata de una modalidad consensual, que subyace en la ejecución de las prácticas instituidas. Esta motivación sin cuestionamientos es muy notoria también en el Poeta, quien no pretende abandonar el Colegio Militar por más violencia e injusticias que se presenten en ese ámbito.

\section{El ajuste}

Asimismo, debe tenerse en cuenta que para regular las conductas del Poeta es necesario el ajuste, el cual es definido por Landowski $(2009$, p.48) como la capacidad de sentirse recíprocamente, es decir, un hacerse conjunto. Para explicar esta modalidad, es necesario conocer los términos que determinan la función del sujeto en cuanto adaptación frente a una instancia. Existen dos tipos de sensibilidades susceptibles que se encargan de fundar los procesos de ajuste. El primero es la sensibilidad perceptiva, la cual permite experimentar, por medio de los sentidos, las variaciones 
perceptibles del mundo exterior (ligadas a la presencia de otros cuerpos-sujetos 0 los elementos del mundo-objeto) y facilita también sentir las modulaciones internas que afectan los estados del cuerpo propio. En la novela, se refiere al impacto que tiene la sociedad violentada en cada uno de los personajes y cómo estos adoptan una postura a seguir, a partir de aquella degradación (el Poeta se inclinará por un comportamiento convencional, en el que él no resulte agredido ni sea objeto de burla). El segundo tipo es denominado la sensibilidad reactiva, que se encarga de interpretar el conjunto de soluciones de continuidad, en términos de sensaciones diferenciadas. Por ejemplo, ocurre cuando se observan objetos sensibles que están construidos por impulsos específicos, de tal manera que reaccionan de modo exacto y al gusto de uno demasiado rápido. En el caso de La ciudad y los perros (1963), se aprecia una distinción explícita: la ciudad es tomada como un elemento degradado que requiere de orden y ética; la escuela militar es tomada como un lugar donde los cadetes aprenderán, con formaciones violentas, una buena conducta que les servirá como compromiso para enrumbar a su sociedad por un camino correcto. El hecho de que estos espacios estén simbolizados evidencia la eficacia del proceso de causalidad: prioridad de este segundo tipo de sensibilidad, la reactiva.

Con el tipo de sensibilidad ya explicado, se observa de qué manera el individuo hace su introducción en este organismo social. El sujeto debe adecuarse a un medio distinto del que proviene y ajustarse a la situación. De forma continua, se aprecia el modo como uno se adecúa a una sociedad y el conocimiento que adquiere de las costumbres de los internos, con la finalidad de analizar y relacionarse con los parámetros que rigen y deconstruyen aquellos espacios violentos. Pero no todo resulta provechoso, la función del Poeta consistió en adecuarse a esa sociedad sin derrocar a las entidades de poder, aunque, al ser invadido por la furia, logra enfrentarse al Jaguar, y, con ello, desequilibra su postura intermedia de no querer sobrepasar los límites ya establecidos por él mismo. Eric Landowski (2009, p. 63) señala que el ajuste es fallido a causa de una sensibilidad mal posicionada. Si el odio se introdujo en el Poeta, luego de que murió el Esclavo, lo más probable es que existiera una forma de reducir ese potencial de venganza al hacer justicia, pero otros factores son los que determinan que Alberto no tome la decisión correcta (la indiferencia de las autoridades militares en hacer público al responsable del homicidio y la tolerancia de las actitudes violentas de los alumnos, en especial de las del Jaguar, provocan que el Poeta se sienta solo en el mundo). 


\section{La racionalidad}

Alberto Fernández tiene la peculiaridad de inducir razonamientos que desembocan en aserciones de la realidad. Se muestra más lúcido en crear e inferir, a diferencia del Esclavo y el Jaguar. Rápidamente, fundamenta la muerte de su amigo sin equivocación alguna; tal como lo demuestra al hablar con el teniente Gamboa, coherente y pretenciosamente, en el siguiente fragmento:

-Sí, mi teniente -dice-. Me hago responsable. Lo mató el Jaguar para vengar a Cava [...]. Todo fue por la consigna, mi teniente. Por lo del vidrio. Para él fue horrible, peor que para cualquiera. Hacía un mes que no salía. Primero le robaron su piyama. Y a la semana siguiente lo consignó usted por soplarme en el examen de química. Estaba desesperado, tenía que salir, ¿comprende usted, mi teniente? [...]. Quiero decir que estaba enamorado, mi teniente. Le gustaba una muchacha. El Esclavo no tenía amigos, hay que pensar en eso, no se juntaba con nadie. Se pasó los tres años del colegio solo, sin hablar con nadie. Todos lo fregaban. Y él quería salir para ver a esa chica. Usted no puede saber cómo lo batían todo el tiempo. Le robaban sus cosas, le quitaban los cigarrillos. (Vargas Llosa, 2012, p.329)

Las aclaraciones señalan que el Jaguar, jefe del Círculo, ha empleado un acto de venganza contra el delator. Postulados que son ciertos y de los cuales no retira su perspectiva. En la cita que coloco a continuación, se valora el énfasis de la delación del Poeta, quien está totalmente decidido en sus convicciones, juzga con la selección y la discriminación hacia el responsable del homicidio.

-¿Q̣ién lo mató?

-El Jaguar, mi teniente. Los otros dos, el Boa y el Rulos son un par de brutos, pero ellos no hubieran disparado. Fue el Jaguar (Vargas Llosa, 2012, p. 331) 


\section{Demarcación identitaria}

Un tópico que se desarrolla funcionalmente es la idea de hacerse notar en un espacio donde resultará de importancia la mirada que se tiene de cada uno, por lo que será de necesidad mostrar y construir un rasgo fundamental de dominación. Para Otto Klineberg (Domenach et al., 1981, p.128), la violencia se convertirá en una manera adaptativa de vivir: tolerable, aceptada y respaldada por los hábitos populares y la moralidad convencional, con los que se formará una subcultura, en la cual se plantea una agresividad intermachos o de competición, encubierta con un aspecto defensivo del territorio. Será siempre un comportamiento adquirido, vinculado con el acceso de objetos gratificantes y el establecimiento de jerarquías dominantes. Se manifiesta en una actitud agresiva o un combate real, con los que se permite el refuerzo de las pulsiones predatorias y los comportamientos agresivos en el dominante. Pero, muchas veces, esta actitud se patentiza de modo inusual; por lo tanto, se alude a una agresividad defensiva. Esta se distingue por caracterizarse como un comportamiento innato que es provocado por un estímulo doloroso, con el cual el desligue es imposible y se piensa, erróneamente, que la persona será recompensada. Ante esta actitud, se presenta una limitación que impide o detiene el constante progreso de la violencia: la punición y el enfrentamiento con acontecimientos no clasificables. Alberto Fernández sabe muy bien cómo debe comportarse para incluirse en el Colegio Militar sin que sea objeto de burlas. Una de las estrategias del Poeta, para no llegar a esa situación, es ofendiendo a quien trate de imponerse sobre él; el hecho de que insulte al negro Vallano con descalificativos raciales no implica que este personaje sea racista, sino que se vale de cualquier artificio para que ni uno de sus compañeros lo derrote mediante la violencia verbal que representa a los demás. Todos sus enemigos o quienes traten de hacerle frente tendrán un motivo para ser menospreciados de alguna forma, así sea forzosa; de esta manera, evita que el personaje se quede callado por un ataque violento que atente contra su integridad. Alberto tendrá que repetir constantemente estas actitudes para evadir una manifestación de violencia ante su persona; no solo eso, deberá molestar también a la persona que destaca por su incompetencia y su debilidad: violentará al Esclavo, como lo hace la mayoría de su sección. Otra característica más en él se inserta al mostrarse una figura del escritor. Como bien señala Enrique Páez (2001, p.396), para ser un escritor, primero, se ha de ser un gran lector. En todo caso, el autor asume incons- 
cientemente que este personaje tiene el hábito de la lectura; por lo tanto, su dominio para escribir queda justificado. Pero no solo es la imagen del escritor la que desea imponer Alberto Fernández, sino que se autorregula a las exigencias adolescentes de los cadetes para escribir acerca de un tema que los conmueve: la pornografía. Al respecto, Tzvetan Todorov (2000) indica lo siguiente: "Cuando los acontecimientos vividos por el individuo o por el grupo son de naturaleza excepcional o trágica, tal derecho se convierte en un deber: el de acordarse, el de testimoniar" (p.18). El Poeta alcanza un prestigio notorio entre los cadetes, porque en sus novelitas denigra a la mujer y habla mal de ella; con esto, resulta posicionarse por encima del concepto de feminidad: lo critica y apoya, a su vez, la cultura machista.

\section{Intento de ser violento}

En La ciudady los perros, los cadetes pretenden imitar al Jaguar en todas sus actitudes, debido a que él infunde temor y respeto, características que provocan interés en los adolescentes del Colegio Militar. Aquel interés lo tiene, de manera implícita, el Poeta. Slavoj Žižek (2008, p.44), desde su perspectiva lacaniana, determina que el deseo del hombre es el deseo del otro; lo que se entenderá como una envidia generada por este, ya que se aprecia en el sujeto referente una obstaculización que impide el éxito de sí mismo, gratitud que no merece, según él, puesto que su persona se encuentra en iguales o semejantes condiciones. Aristóteles (1990, p.368) añade que son más envidiosos los que ambicionan honores. En el caso del Poeta, se observa que toma como modelo en su colegio al Jaguar, porque él posee casi lo más importante (respeto, amigos a su disposición y habilidad en pelear). Cuando el Esclavo conversa con Alberto, se revela esa actitud explícita.

-Y tú imitas la risa del Jaguar - dice el Esclavo, suavemente-; eso debería darte más pena [...].

Alberto ríe. Su risa se corta bruscamente.

-Es verdad -dice-. Me estoy riendo como el Jaguar. ¿Por qué lo imitan todos? (Vargas Llosa, 2012, pp. 25-26)

Si el Poeta insinuara ser como el Jaguar, tendría que convertirse en una entidad monstruosa. Aquello resulta posible cuando se desafían entre ellos al estar 
encerrados por el teniente Gamboa en la misma celda. Un planteamiento similar era sostenido por Fernando Savater (2005, p.99), quien observaba que la paciencia tiene un límite; sobre todo, si existe una recarga de inacciones ante conductas violentas e injustas que propaga el otro, ya que uno mismo se delimita al no ser realmente quien es. Por lo tanto, una persona con un habitual genio conllevará una actitud controlable, mientras que una que pierde los nervios ocasionalmente, llegará a desentrañar una acción de la cual él mismo no cree que sea posible realizarse en un estado normal. El Poeta, al pelear contra el Jaguar, no piensa en los resultados; por eso, ese retorno al estado salvaje es propicio tan solo cuando se presentan situaciones de alto desarrollo de poder. De esta forma, uno que piensa en sí mismo y quiere superarse adquirirá la violencia al sentirse frustrado o imposibilitado de sobresalir.

\section{Riesgo en la autorregulación}

El riesgo está articulado en el personaje del Poeta. Este trance se produce cuando este es patentizado ante una situación en la que se consiguen resultados desfavorables, ya sea por las circunstancias o las cualidades limitadas que él presente. En la novela de Vargas Llosa, hay un ejemplo considerable al observar cómo el Poeta pretende quitarle el poder al Jaguar. Se sabe que la ira que tiene hacia el líder del Círculo es pretexto para pelear contra él, pero ello no permite que adquiera de forma inexplicable toda una sabiduría callejera y un conocimiento de combate. El exponerse a luchar con el más temible de la sección del Colegio Militar lo conduce a un error determinante: salir lastimosamente dañado o morir, mas no vencer. Al respecto, Sigmund Freud (2004, p.436) postula que la necesidad misma obliga a un hombre a sacrificar su salud, siempre y cuando, el caso sea detectado y justificado como la única manera de evitar una inmensa desgracia, de la que sufriría él y un determinado grupo social. El Poeta, al enfrentar al Jaguar, quiere hacer justicia por la muerte provocada al Esclavo, el sufrimiento infundido a los padres de la víctima y el ocaso espiritual que posee este protagonista al haber perdido a uno de sus mejores amigos.

\section{Limitaciones identitarias}

A pesar de que el Poeta cuenta con la intención de imitar al Jaguar de algún modo, él se halla imposibilitado de serlo. Lo que lo hace distinto es su lado humano: Alberto Fernández cuando tiene que llorar lo hará, tal como ocurre por la muerte del Esclavo. 
Varios le preguntaron qué había ocurrido. Pero él no les hizo caso ni pareció darse cuenta minutos más tarde, cuando Vallano, que marchaba a su lado, dijo en voz bastante alta para que oyera toda la sección: "El Poeta está llorando". (Vargas Llosa, 2012, p.303)

Alberto pretende derrocar al Jaguar en una pelea, aunque no podrá, porque está imposibilitado físicamente y no sabe pelear tanto como él, carece de práctica constante de violencia.

\section{Una identidad acobardada}

Existe en el Poeta rasgos del Esclavo, como el del silencio convencional. Este se aprecia cuando las autoridades del Colegio Militar Leoncio Prado lo chantajean; inmediatamente, él se convierte en un traidor. Alberto Fernández tiene dos momentos importantes en los que el silencio es relacionado con la cobardía y la protección personal. La primera ocasión se muestra cuando el Jaguar es acusado de soplón; en ese momento, la preferencia por no revelar la verdad se oculta tras el temor de que el Poeta resulte golpeado por toda la sección. La segunda oportunidad está cuando Alberto no debe mencionar nada en función del culpable del asesinato del Esclavo, ya que de hacerlo será expulsado del Colegio Militar por haber escrito novelitas pornográficas.

\section{Conclusiones}

De los personajes de La ciudad y los perros, el más prudente de todos resulta ser Alberto Fernández (el Poeta), quien adopta una postura que se adapta a cada situación. Su lucha constante interna se desarrolla en función del deseo de ser admirado por sus demás compañeros (para ello, debe demostrar y actuar de manera violenta) y hacer relucir su humanismo (el cual lo hace de forma invisibilizada o fuera de aquellos que pudieran ser testigos de que adopta únicamente conductas agresivas). La finalidad de Alberto Fernández es sobrevivir: aquello lo logra porque, prácticamente, termina el Colegio Militar Leoncio Prado con un proyecto en mente y sin daño alguno. 


\section{Referencias bibliográficas}

Aristóteles (1990). Retórica. Madrid: Gredos.

Castro-Klarén, S. (1992). Understanding Mario Vargas Llosa. Columbia, EE. UU.: University of South Carolina Press.

Delgado Del Águila, J. M. (2017). Protagonismo violento y modos de representación en La ciudad y los perros (1963). (Tesis de licenciatura). Universidad Nacional Mayor de San Marcos, Lima.

Domenach, J., Joxe, A., Galtung, J., et al. (1981). La violencia y sus causas. París: Editorial de la Unesco.

Freud, S. (2004). Introducción al psicoanálisis. Madrid: Alianza Editorial.

Lacan, J. (1997). El seminario. Libro 7. La ética del Psicoanálisis. Buenos Aires: Paidós.

Landowski, E. (2007). Presencias del otro. Lima: Fondo Editorial de la Universidad de Lima.

Landowski, E. (2009). Interacciones arriesgadas. Lima: Fondo Editorial de la Universidad de Lima.

Páez, E. (2001). Escribir. Manual de técnicas narrativas. Madrid: Ediciones SM.

Savater, F. (2005). Los siete pecados capitales. Buenos Aires: Editorial Sudamericana.

Sen, A. (2007). Identidad y violencia. La ilusión del destino. Buenos Aires: Katz Editores.

Todorov, T. (2000). Los abusos de la memoria. Barcelona: Paidós.

Vargas Llosa, M. (2012). La ciudad y los perros. Edición conmemorativa del cincuentenario. Italia: Alfaguara, Real Academia Española.

Vilela Galván, S. (2003). El cadete Vargas Llosa: Ia historia oculta tras "La ciudad y los perros". Santiago de Chile: Planeta.

Žižek, S. (2008). Cómo leer a Lacan. Buenos Aires: Paidós. 